\title{
Morfogênese na germinação e na fase de estabelecimento da Brachiaria ruziziensis submetida à adubação nitrogenada e potássica
}

\author{
Morphogenesis in the germination and establishment phase of Brachiaria ruziziensis subjected to \\ fertilization with nitrogen and potassium
}

\author{
Marcelo Barcelo Gomes $^{I^{*}}$ Vera Lúcia Banys ${ }^{I}$ Juliana Santos ${ }^{I}$ Ana Luisa Aguiar de Castro

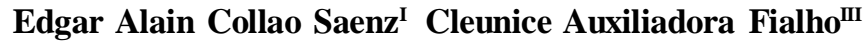

RESUMO

\begin{abstract}
Este estudo foi realizado com o objetivo de avaliar as respostas morfogênicas da Brachiaria ruziziensis submetida à adubação nitrogenada e potássica na germinação e na fase de estabelecimento. Adotou-se esquema fatorial $4 \times 4$ em DIC, com três repetições. Foram utilizadas as doses 0, 100, $200 e$ $300 \mathrm{~kg} \mathrm{~N} \mathrm{ha} \mathrm{H}^{-1}$ e as doses de 0, 60, 90 e $120 \mathrm{~kg} \mathrm{~K} \mathrm{ha}^{-1}$. Verificouse, na avaliação na germinação, efeito da interação $N \times K$ na TAlC. Houve efeito isolado das doses de nitrogênio sobre a TApF, TAlF, filocrono, NFV e TSF. $O$ potássio exerceu efeito isolado sobre a DVF e NFV. Na avaliação de estabelecimento, observou-se que houve efeito da interação $N \times K$ para TAlF e CFF. Houve efeito isolado das doses de nitrogênio sobre a TApF, TAlC, filocrono, NFV, TSF e DVF. O potássio exerceu efeito isolado sobre a DVF, NFV e TSF. Tanto na germinação quanto no estabelecimento, o nitrogênio exerceu maior efeito sobre a morfogênese do que o potássio.
\end{abstract}

Palavras-chave: alongamento, colmo, filocrono, interação, senescência.

\section{ABSTRACT}

This study was conducted to assess the morphogenic responses of Brachiaria ruziziensis subjected to nitrogen and potassium fertilization in the germination and establishment phase. It was used a complete randomized experimental design in $4 \times 4$ factorial arrangement with three replicates. There were used 0,100, 200 and $300 \mathrm{~kg} \mathrm{~N} \mathrm{ha}^{-1}$ and 0,60, 90 and $120 \mathrm{~kg} \mathrm{~K}$ $h a^{-1}$. In the germination, it was verified the effect of the interaction $N \times K$ in SER. There was isolated effect of nitrogen doses on LAR, LER, phyllochron, LLN, LSR. Potassium exerted isolated effect on the LLS and LLN. In the established phase, it was observed that there was a significant interaction between $N \times K$ for LER and LFL. There was isolated effect of nitrogen on LAR,
SER, phyllochron, LLN, LSR and LLS. Potassium exerted isolated effect on LLS, LLN and LSR. Nitrogen had greater effect on the morphogenesis than potassium on both, germination and established phase.

Key words: elongation, stem, phyllochron, interaction, senescence.

\section{INTRODUÇÃO}

A produtividade das gramíneas decorre da contínua emissão de folhas e é um processo importante após o corte e, por isso, a utilização de recursos que priorizem o surgimento de novas folhas é fundamental para a recuperação da sua eficiência fotossintética. Morfogênese é a dinâmica de geração e expansão da planta no espaço (CHAPMAN \& LEMAIRE, 1993) e, em algumas espécies de clima tropical, particularmente nas de hábito de crescimento ereto, o alongamento de colmos torna-se importante componente do crescimento, interferindo significativamente na estrutura do pasto e no equilíbrio dos processos de competição por luz (SBRISSIA et al., 2001). Quando as condições de ambiente são ideais e não há limitação na disponibilidade de outros nutrientes, o $\mathrm{N}$ afeta a expressão das variáveis morfogênicas aumentando a taxa de alongamento de folhas e a taxa de aparecimento de perfilhos (HODGSON, 1990; LEMAIRE \& CHAPMAN, 1996).

\footnotetext{
'Programa de Pós-graduação em Agronomia, Campus Jataí, Universidade Federal de Goiás (UFG), CP 03, 75801-615, Jataí, GO, Brasil. E-mail: gomes_mb@yahoo.com.br.*Autor para correspondência.

"Curso de Zootecnia, Campus Jataí, UFG, Jataí, GO, Brasil.

IIIPrograma de Pós-graduação em Ciência Animal e Pastagens, Departamento de Zootecnia, ESALQ, Piracicaba, SP, Brasil.
} 
O potássio $(\mathrm{K})$ é o cátion em maior concentração nas plantas pelas suas funções fisiológicas e metabólicas, porém, dependente da nutrição nitrogenada (ROSOLEM, 2005).

Objetivou-se avaliar as respostas morfogênicas da $\boldsymbol{B}$. ruziziensis submetida à adubação nitrogenada e potássica na germinação e estabelecimento.

\section{MATERIAL E MÉTODOS}

O experimento foi conduzido em casa de vegetação, na Universidade Federal de Goiás, Campus Jataí, Estado de Goiás, nas coordenadas $17^{\circ} 55^{\prime} 17^{\prime \prime}$ de latitude Sul e 51\%3'05" de longitude Oeste, altitude de $652 \mathrm{~m}$, com clima classificado como Aw (Köppen), com temperatura média anual de $22^{\circ} \mathrm{C}$, utilizando-se sementes de Brachiaria ruziziensis, quatro doses de nitrogênio $\left(0,100,200\right.$ e $\left.300 \mathrm{~kg} \mathrm{ha}^{-1}\right)$ e quatro doses de potássio $\left(0,60,90\right.$ e $\left.120 \mathrm{~kg} \mathrm{ha}^{-1}\right)$, em delineamento inteiramente casualizado, em arranjo fatorial $4 \times 4$, com três repetições, em que três perfilhos/vaso foram avaliados duas vezes por semana e totalizando 144 perfilhos. Utilizou-se um Latossolo Vermelho distroférrico (EMBRAPA, 2009), homogeneizado, peneirado e corrigido para $60 \%$ de saturação por bases, em vasos de $7,5 \mathrm{dm}^{3}$ em que 30 sementes vaso ${ }^{-1}$ foram semeadas em novembro simultaneamente à aplicação do $\mathrm{N}$ (sulfato de amônia), do $\mathrm{K}_{2} \mathrm{O}$ (cloreto de potássio), de $180 \mathrm{~kg} \mathrm{ha}^{-1}$ de $\mathrm{P}_{2} \mathrm{O}_{5}$ (superfosfato simples) e $10 \mathrm{~kg} \mathrm{ha}^{-1}$ de micronutrientes $(1,6 \% \mathrm{~B}, 1,6 \% \mathrm{Cu}, 8 \% \mathrm{Mn}$ e $12 \%$ $\mathrm{Zn}$ ). A irrigação foi diária e manual até a formação de uma lâmina de água na superfície do solo. Três dias após a germinação, fez-se o desbaste, deixando-se cinco plântulas vaso $^{-1}$, sendo três identificadas para a morfogênese. Aos 35 dias após a emergência, efetuouse um corte a $5 \mathrm{~cm}$ do solo, finalizando-se o período de germinação e iniciando as avaliações de estabelecimento até os 35 dias. Avaliou-se o aparecimento do ápice foliar, dia da exposição da lígula, comprimento do pseudocolmo, comprimento da lâmina foliar expandida e em expansão, número de folhas por perfilho, número de folhas vivas, mortas e em senescência, segundo OLIVEIRA et al. (2007), e calculou-se a taxa de aparecimento foliar (TApF) em folhas $\mathrm{dia}^{-1}$; filocrono - tempo decorrido entre o aparecimento de duas folhas (dia folha ${ }^{-1}$ ); taxa de alongamento foliar (TAlF) em $\mathrm{cm}^{-1}$ perfilho-1 dia; taxa de alongamento do colmo (TAlC) em $\mathrm{mm}^{-1}$ perfilho- dia; taxa de senescência foliar (TSF) em cm${ }^{-1}$ perfilho ${ }^{-1}$ dia; número de folhas verdes (NFV) em folhas; comprimento final da folha (CFF) em cm; duração de vida da folha (DVF) em dias e todos os dados foram analisados pelo $\mathrm{SAS}^{\circledast}$, versão 9.0 , a $5 \%$ de probabilidade com comparação dos níveis de adubação por contrastes ortogonais e posterior ajuste de regressão.

\section{RESULTADOS E DISCUSSÃO}

Observou-se efeito da interação N x K para TAlC na germinação e TAlF e CFF no estabelecimento, para doses de nitrogênio, tanto na germinação quanto no estabelecimento sobre as variáveis TApF, TSF, filocrono e NFV, para TAlF na germinação e para TAlC e DVF no estabelecimento. O potássio apresentou efeito isolado sobre a DVF e NFV no período de germinação e de estabelecimento e sobre a TSF no estabelecimento. Houve efeito quadrático negativo para TAlC em função das doses crescentes de nitrogênio, na dose de $60 \mathrm{~kg}$ de $\mathrm{K} \mathrm{ha}^{-1}$. A dose de nitrogênio que proporcionou o menor crescimento do pseudocolmo foi $232 \mathrm{~kg}$ de $\mathrm{N} \mathrm{ha}^{-1}$. CARVALHO et al. (1991) observaram que a adubação nitrogenada aumentou a produção de massa seca quando as doses de potássio foram adequadas. MATTOS \& MONTEIRO (1998), em estudo feito sobre a resposta da $\boldsymbol{B}$. brizantha a doses de potássio, observaram que colmos e bainhas apresentaram a maior fração de potássio na parte aérea e MAGALHÃES et al. (2007) observaram que a aplicação de nitrogênio eleva a produção de matéria seca (MS) de folhas e de colmos, proporcionando aumento na relação folha: colmo. A interação N x K apresentou efeito quadrático positivo em função das doses de potássio, nas doses de 100 e $300 \mathrm{~kg} \mathrm{de} \mathrm{N} \mathrm{ha}^{-1}$ sobre a TAlC. Na dose $100 \mathrm{~kg}_{\text {de }} \mathrm{N} \mathrm{ha}^{-1}$, observou-se TAlC máxima de $8,64 \mathrm{~mm} \mathrm{dia}^{-1}$ na dose $104 \mathrm{~kg}$ de $\mathrm{K} \mathrm{ha}^{-1} \mathrm{e}$ na dose $300 \mathrm{~kg}$ de $\mathrm{N} \mathrm{ha}^{-1}$ houve maior resposta da TAlC $\left(9,84 \mathrm{~mm} \mathrm{dia}^{-1}\right)$ na dose $96,75 \mathrm{~kg} \mathrm{ha}^{-1}$ de K (Figura 1). O alongamento do colmo em gramíneas tropicais se deve a dois motivos principais: baixa frequência de desfolhação e florescimento (CARNEVALLI, 2003). Cortes menos intensos e frequentes ocasionam maior florescimento, maior produção de pseudocolmo e de material morto (MARCELINO et al., 2006). Nas condições deste experimento, pelo fato da $\boldsymbol{B}$. ruziziensis ter crescimento livre sem desfolhações frequentes, as taxas de crescimento do colmo apresentaram resposta aos níveis de adubação, mesmo sem a presença de florescimento, podendo ser justificadas pela ausência de manejo. Houve resposta linear positiva da TAlC em função das doses de $\mathrm{N}$ durante o estabelecimento. $\mathrm{O}$ menor crescimento do pseudocolmo foi de $2,82 \mathrm{~mm} \mathrm{dia}^{-1}$ na dose $0 \mathrm{~kg} \mathrm{de} \mathrm{N} \mathrm{ha}^{-1}$ e a maior TAIC foi de $4,05 \mathrm{~mm} \mathrm{dia}^{-1}$ na dose $200 \mathrm{~kg}$ de N $\mathrm{ha}^{-1}$. CURCELLI (2009) encontrou TAlC de $1 \mathrm{~mm} \mathrm{dia}^{-1}$ para o período de estabelecimento de 28 dias do capim- 


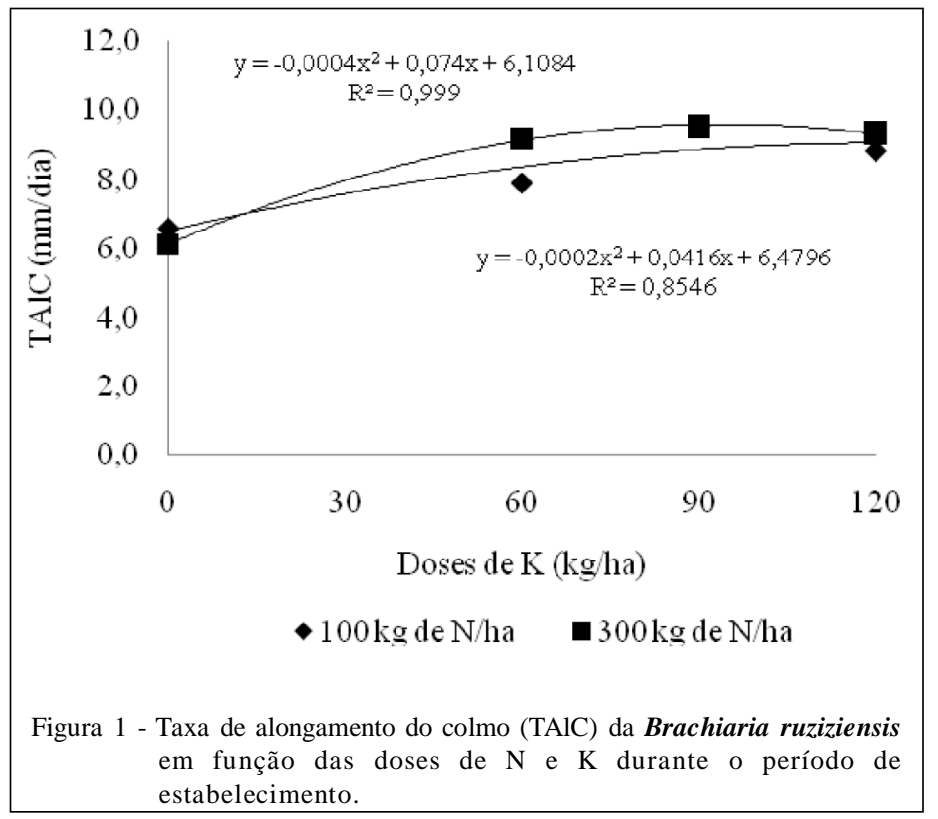

xaraés (B. brizantha cv. 'Xaraés'), em condições de ambiente não controladas.

Doses crescentes de $\mathrm{N}$ proporcionaram aumento linear positivo à taxa de aparecimento foliar (TApF) durante a germinação, sendo o maior valor $(0,39$ folhas dia $^{-1}$ ) observado na dose $300 \mathrm{~kg} \mathrm{~N} \mathrm{ha}^{-1}$. OLIVEIRA et al. (2007) observaram que as combinações de adubação contendo $\mathrm{N}$ proporcionaram maior TApF, sendo encontrados 0,$21 ; 0,20$ e 0,18 folhas dia $^{-1}$ para as combinações NK, NPe NPK, respectivamente. Apesar do efeito positivo do $\mathrm{N}$ sobre a TApF e TAlF, não houve efeito significativo sobre o CFF. $O$ fato de ter havido interação N x K sobre a TAlC explica esse efeito, uma vez que não houve resposta dessas variáveis em função do K. Observou-se resposta linear positiva da TApF em função do $\mathrm{N}\left(0,21\right.$ e 0,26 folhas dia $^{-1}$ nas doses 0 e $200 \mathrm{~kg}$ de $\mathrm{N} \mathrm{ha}^{-1}$, respectivamente) durante o estabelecimento. MARTUSCELLO et al. (2005), em experimento com B. brizantha $\mathrm{cv}$. 'Xaraés', adubada com quatro doses de nitrogênio $\left(0,80,160\right.$ e $\left.240 \mathrm{~kg} \mathrm{ha}^{-1}\right)$ e submetida a três regimes de desfolhação (três, quatro e cinco folhas completamente expandidas), observaram que a TApF respondeu linear e positivamente às doses de N, sendo obtidos valores de 0,096 (sem adubação nitrogenada) e 0,121 folhas $\operatorname{dia}^{-1}\left(240 \mathrm{~kg} \mathrm{ha}^{-1}\right)$ que correspondeu ao aumento de $26 \%$ em relação à ausência de N, e, nas condições deste trabalho, houve aumento de $23 \%$ na TApF. Quando há alta disponibilidade de $\mathrm{N}$, ocorre elevada estimulação do crescimento da planta, com consequente alongamento dos entrenós, empurrando a folha nova para fora da bainha da folha precedente, o que pode causar aumento da TApF (OLIVEIRA et al., 2007).

O filocrono indica o tempo (em dias ou em graus-dia) necessário para o aparecimento de duas folhas consecutivas e apresentou resposta linear negativa para as doses de $\mathrm{N}$ no estabelecimento. $\mathrm{O}$ maior e o menor valor do filocrono foi de 2,96 e 2,60 dias para as doses de 0 e $300 \mathrm{~kg} \mathrm{ha}^{-1}$ de $\mathrm{N}$, respectivamente. LAVRES JR. et al. (2004), em trabalho com capim-aruanã (Panicum maximum cv. 'Aruanã') adubado com seis doses de $\mathrm{N}(28,224,420,588,756 \mathrm{e}$ $924 \mathrm{~kg} \mathrm{ha}^{-1}$ ), observaram, aos 35 dias de crescimento, que o filocrono variou de 2,02 a 0,75 dias folha $^{-1}$ quando a dose de $\mathrm{N}$ passou de 28 para $420 \mathrm{~kg} \mathrm{ha}^{-1}$, quando apresentou melhor resultado. Quanto maior o suprimento de $\mathrm{N}$, menor o tempo necessário para o aparecimento de duas folhas sucessivas e, portanto, maior número de folhas constitui o perfilho, o que é desejável. O filocrono respondeu de forma linear negativa ao $\mathrm{N}$ (4,77 dias na dose $0 \mathrm{~kg}$ de $\mathrm{N} \mathrm{ha}^{-1}$ e 3,92dias folha ${ }^{-1}$ na dose $200 \mathrm{~kg}$ de $\mathrm{N} \mathrm{ha}^{-1}$ ). ALEXANDRINO et al. (2004) encontraram valores de filocrono de 12,20; 8,47 e 6,99dias folha ${ }^{-1}$ durante o estabelecimento de $\boldsymbol{B}$. brizantha, cv. 'Marandu', adubado com 0, 40 e $80 \mathrm{~kg}$ de $\mathrm{N} \mathrm{ha}^{-1}$ semana $^{-1}$. Tanto na germinação quanto no estabelecimento, o filocrono apresentou respostas semelhantes em escalas diferentes, mas concomitantemente inversos à $\mathrm{TApF}$, indicando maior número de folhas com o aumento das doses de $\mathrm{N}$.

A maior taxa de alongamento foliar (TAIF) de $7,59 \mathrm{~cm} \mathrm{dia}^{-1}$ foi observada na dose $300 \mathrm{~kg}$ de $\mathrm{N} \mathrm{ha}^{-1}$ 
durante a germinação. OLIVEIRA et al. (2007) observaram que o $\mathrm{N}$ proporcionou aumento médio de $90 \%$ na TAlF no capim-tanzânia. As gramíneas apresentam alongamento foliar a partir de uma zona na sua base, responsável pela divisão celular e que apresenta grande acúmulo de $\mathrm{N}$, evidenciando a estreita relação entre o suprimento desse nutriente da folha em expansão. Observou-se efeito significativo da interação $\mathrm{N} x$ K na taxa de alongamento foliar (TAlF) durante o estabelecimento da B. ruziziensis, resultando em resposta linear positiva na dose $0\left(1,81\right.$ e $3,23 \mathrm{~cm} \mathrm{dia}^{-1}$ nas doses 0 e $300 \mathrm{~kg}$ de $\mathrm{N} \mathrm{ha}^{-1}$, respectivamente) e menores na dose de $60 \mathrm{~kg}$ de $\mathrm{K} \mathrm{ha}^{-1}\left(1,47 \mathrm{e} 2,65 \mathrm{~cm} \mathrm{dia}^{-1}\right.$ nas doses de 0 a $300 \mathrm{~kg}$ de $\mathrm{N} \mathrm{ha}^{-1}$, respectivamente, (Figura 2). A TAlF apresentou resposta linear negativa em função do $\mathrm{K}$ na dose de $200 \mathrm{~kg}$ de $\mathrm{N} \mathrm{ha}^{-1}(3,23 \mathrm{a}$ $1,8 \mathrm{~cm} \mathrm{dia}{ }^{-1}$, nas doses de 0 a $120 \mathrm{~kg}$ de $\mathrm{K} \mathrm{ha}^{-1}$, respectivamente). CARVALHO et al. (1991) observaram que a adubação nitrogenada aumentou a produção de massa quando a dose de $\mathrm{K}$ foi adequada. $\mathrm{O}$ alongamento foliar foi influenciado pelo suprimento de nitrogênio, afetando diretamente a TAlF em até $80 \%$ na TAlF na dose de $300 \mathrm{~kg}$ de $\mathrm{N} \mathrm{ha}^{-1}$, como relatado por GARCEZ NETO et al. (2002), que obtiveram aumento médio de 52, 92 e 133\% na TAlF nas doses 100, 200 e $400 \mathrm{~kg}$ de $\mathrm{N} \mathrm{ha}^{-1}$ em Panicum maximum $\mathrm{cv}$. 'Mombaça'.

O comprimento final da folha (CFF) foi influenciado pela interação $\mathrm{N}$ x K no estabelecimento, respondendo linear e positivamente em função do $\mathrm{N}$ na dose de $60 \mathrm{~kg}$ de $\mathrm{K} \mathrm{ha}^{-1}(11,39$ a $16,11 \mathrm{~cm}$, nas doses de 0 a $300 \mathrm{~kg}$ de $\mathrm{N} \mathrm{ha}^{-1}$, respectivamente) e negativamente em função do K na dose de $200 \mathrm{~kg}$ de N $\mathrm{ha}^{-1}\left(15,96\right.$ a $12,66 \mathrm{~cm}$, nas doses de 0 e $\left.120 \mathrm{~kg} \mathrm{de} \mathrm{K} \mathrm{ha}^{-1}\right)$. A TApF não foi influenciada pelo $\mathrm{K}$ durante o estabelecimento, porém apresentou aumento em função das doses de $\mathrm{N}$ influenciarem o CFF (Figura 3), admitindo que o aumento da concentração de $\mathrm{K}$ diminuiu o CFF e a TAlF, porém houve aumento da DVF e NFV e diminuição da TSF. Além disso, houve a diminuição do colmo em função das doses de K, resultando em menor percurso para a lâmina foliar percorrer para emergir do pseudocolmo.

A taxa de senescência foliar (TSF) apresentou valores máximos e mínimos de 1,39 e $0,84 \mathrm{~cm}$ dia $^{-1}$ para as doses de 300 e $0 \mathrm{~kg}$ de $\mathrm{N} \mathrm{ha}^{-1}$ na germinação. MARTUSCELLO et al. (2005) observaram valores de 0,36 e $0,77 \mathrm{~cm} \mathrm{dia}^{-1}$ nas doses de 0 e $240 \mathrm{~kg}$ de $\mathrm{N} \mathrm{ha}^{-1}$, respectivamente. À medida que a folha senesce, há, consequentemente, a morte do tecido foliar que impede balanço positivo do número de folhas verdes importantes no manejo e na manutenção do valor nutritivo das forrageiras. No estabelecimento, a TSF apresentou resposta linear positiva às doses de $\mathrm{N}(0,13$; 0,$41 ; 0,72$ e $0,92 \mathrm{~cm} \mathrm{dia}^{-1}$ nas doses de $0,100,200 \mathrm{e}$ $300 \mathrm{~kg}$ de $\mathrm{N} \mathrm{ha}^{-1}$ ), indicando que, na ausência de $\mathrm{N}$, as plantas permanecem com baixa TSF, usando o decréscimo metabólico como estratégia de sobrevivência (Figura 1). Apesar da interação N x K não ter sido significativa no período de estabelecimento, as doses de $\mathrm{K}$ influenciaram significativamente a TSF, que respondeu de forma linear negativa $\left(1,09\right.$ e $0,25 \mathrm{~cm}^{-1 i a}{ }^{-1}$ nas doses 0 e $120 \mathrm{~kg}$ de $\mathrm{K}$ $\left.\mathrm{ha}^{-1}\right)$, evidenciando haver pouca participação do potássio na morte de tecidos foliares.

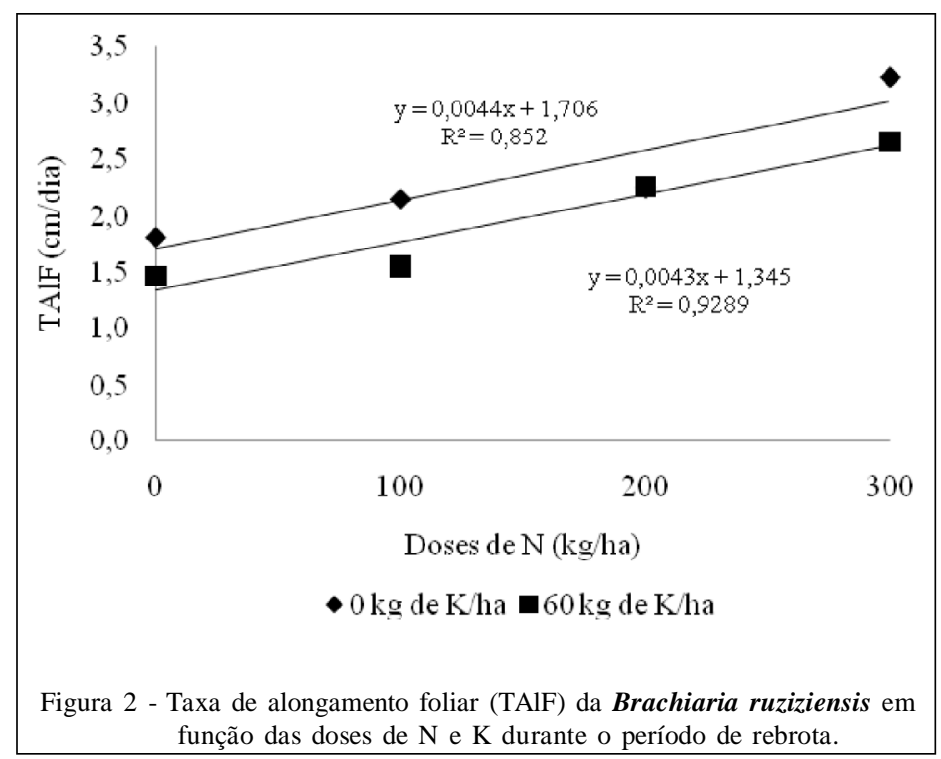

Ciência Rural, v.42, n.12, dez, 2012. 

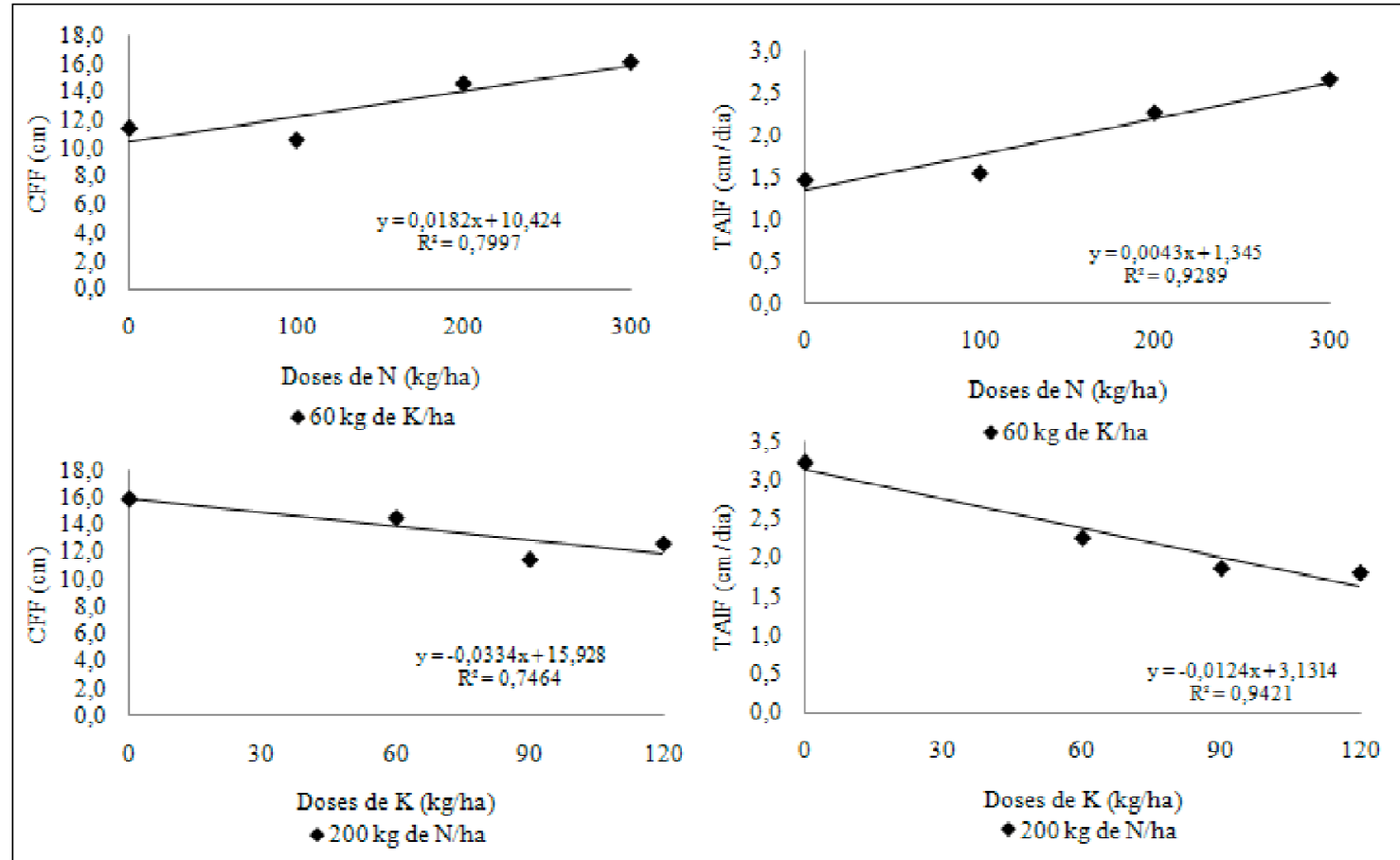

Figura 3 - Taxa de alongamento foliar (TAlF) e comprimento final da folha (CFF) da Brachiaria ruziziensis em função das doses de $\mathrm{N}$ e $\mathrm{K}$ durante o período de rebrota.

Não houve interação entre os nutrientes sobre o número de folhas verdes (NFV) no período de germinação. As doses 0 e $90 \mathrm{~kg}$ de $\mathrm{K} \mathrm{ha}^{-1}$ resultaram valores entre 5,00 e 6,39 folhas perfilho ${ }^{-1}$, respectivamente, e as doses 0 e $300 \mathrm{~kg}$ de $\mathrm{N} \mathrm{ha}^{-1}$ resultaram em resposta linear positiva que variou de 5,05 a 6,28 folhas, respectivamente. SILVA (2006) observou 5,4 folhas na dose de $324 \mathrm{~kg}$ de $\mathrm{N} \mathrm{ha}^{-1}$ para a B. decumbens. O NFV encontrado foi semelhante nas adubações nitrogenada e potássica, fato associado ao estímulo de $\mathrm{N}$ à produção de novos tecidos, concomitante com o maior suprimento de $\mathrm{K}$. O aumento do $\mathrm{N}$ provocou efeito linear negativo no NFV $(4,86 \mathrm{e}$ 3,61 folhas perfilho ${ }^{-1}$ para as doses 0 e $300 \mathrm{~kg} \mathrm{de} \mathrm{Nha}^{-1}$, respectivamente), durante o estabelecimento. PATÊS et al. (2007) observaram efeito linear decrescente no $\mathrm{NFV}$ em capim-tanzânia em função de doses de $\mathrm{N}(0 \mathrm{e}$ $100 \mathrm{~kg}$ de $\mathrm{N} \mathrm{ha}^{-1}$ ), explicada pela diminuição da DVF com o aumento das doses de $\mathrm{N}$ durante o processo de estabelecimento. O NFV respondeu de forma linear positiva ao $\mathrm{K}(3,69 \mathrm{e} 4,89$ folhas nas doses $0 \mathrm{e} 120 \mathrm{~kg}$ de $\mathrm{K} \mathrm{ha}^{-1}$ ) durante o estabelecimento, demonstrando que o potássio promoveu a retenção de folhas verdes, provavelmente, por não estar envolvido diretamente na senescência das folhas, uma vez que a DVF apresentou resposta linear positiva às doses de $\mathrm{K}(14,55$ e 20,70 dias nas doses de 0 e $120 \mathrm{~kg}$ de $\mathrm{K} \mathrm{ha}^{-1}$, respectivamente).

A duração de vida da folha (DVF) apresentou resposta linear positiva para as doses de $\mathrm{K}$ no período de germinação e o valor máximo observado foi de 17,77 dias na dose $120 \mathrm{~kg}$ de $\mathrm{K} \mathrm{ha}^{-1}$. O suprimento adequado de potássio mantém o estoque de carboidratos nãoestruturais, estando ligado ao seu transporte e, consequentemente, ao metabolismo nitrogenado vegetal (COUTINHO et al., 2004). MARTUSCELLO et al. (2005) encontraram resposta linear negativa da adubação nitrogenada à DVF, sendo que, na ausência do $\mathrm{N}$ as folhas, permaneceram mais tempo vivas nas plantas em detrimento da expansão de novas folhas. A DVF apresentou resposta linear negativa ao $\mathrm{N}$ durante $\mathrm{o}$ estabelecimento. Os valores foram de 22,80; 19,44; 17,61 e 13,79 dias nas doses $0,100,200$ e 300kg de $\mathrm{N} \mathrm{ha}^{-1}$, respectivamente. Uma vez estabelecida a senescência, em função da DVF ter sido atingida, boa parte do N é remobilizada para as folhas mais novas, contribuindo de forma significativa para a redução da atividade fotossintética de folhas mais velhas. 


\section{CONCLUSÃO}

A adubação nitrogenada exerce maior influência sobre o ritmo morfogênico de B. ruziziensis, enquanto que a adubação potássica aumenta a duração de vida da folha, o número de folhas viva por perfilho e reduz a taxa de senescência foliar. Recomenda-se as doses de $60 \mathrm{~kg}$ de $\mathrm{K} \mathrm{ha}^{-1}$, associadas a níveis iguais ou superiores a $200 \mathrm{~kg}$ de $\mathrm{N} \mathrm{ha}^{-1}$.

\section{REFERÊNCIAS}

ALEXANDRINO, E. et al. Características morfogênicas e estruturais na rebrotação da Brachiaria brizantha cv. 'Marandú' submetida a três doses de nitrogênio. Revista Brasileira de Zootecnia, Brasília, v.33, n.6, p.1372-1379, 2004. Disponível em: 〈http://www.scielo.br/ scielo.php? script=sci_arttext\&pid=S1516-35982004000600003 >. Acesso em: 12 jul. 2012. doi: 10.1590/S1516-35982004000600003.

CARNEVALLI, R.A. Dinâmica da rebrotação de pasto de capim-mombaça submetidos a regimes de desfolhação intermitente. 2003. 136f. Tese (Doutorado em Ciência Animal e Pastagens) - Curso de Pós-graduação em Ciência Animal e Pastagens, Universidade de São Paulo.

CARVALHO, M.M. et al. Resposta de uma espécie de braquiária à fertilização com nitrogênio e potássio em um solo ácido. Revista Brasileira de Ciência do Solo, Viçosa, v.15, p.195200, 1991.

COUTINHO, E.L.M. et al. Adubação potássica em forrageiras. In: SIMPÓSIO SOBRE MANEJO DA PASTAGEM, 21., 2004, Piracicaba, SP. Anais... Piracicaba: FEALQ, 2004. p.219-277.

CURCELLI, F. Respostas morfogênicas e dinâmica de acúmulo de forragem do capim-xaraés [Brachiaria brizantha (A. Rich.) Stapf. cv. 'Xaraés'] submetido a estratégias de pastejo rotativo. 2009. 90f. Dissertação (Mestrado em Ciência Animal e Pastagens) - Curso de Pós-graduação em Ciência Animal e Pastagens, Universidade de São Paulo.

CHAPMAN, D.F.; LEMAIRE, G. Morphogenic and structural determinants of plants regrowth after desfoliation. In: BAKER, M.J. (Ed.). Grasslands for our world. Wellington: SIR, 1993. Cap.3, p.55-64.

EMPRESA BRASILEIRA DE PESQUISA AGROPECUÁRIA EMBRAPA. Centro Nacional de Pesquisa de Solos. Sistema brasileiro de classificação de solos. Rio de Janeiro: Embrapa Produção de Informação, 2009. 412p.

GARCEZ NETO, A.F. et al. Respostas morfogênicas e estruturais de Panicum maximum cv. 'Mombaça' sob diferentes níveis de adubação nitrogenada e alturas de corte. Revista Brasileira de Zootecnia, Brasília, v.31, n.5, p.1890-1900, 2002. Disponível em: <http:// www.scielo.br/scielo.php?script=sci_arttext\&pid=S1516$35982002000800004 \& \operatorname{lng}=e n \& n r m=i s o>$. Acesso em: 12 jul. 2012. doi: $10.1590 / \mathrm{S} 1516-35982002000800004$.

HODGSON, J. Grazing management: science into practice. Hong Kong: Longman Scientific \& Technical, 1990. 203p.
LAVRES JR., J. et al. Yield components and morphogenesis of aruana grass in response to nitrogen supply. Scientia Agrícola, Piracicaba, v.61, n.6, p.632-639, 2004. Disponível em: <http:/ $/ \mathrm{www}$.scielo.br/scielo.php? script=sci_arttext\&pid=S0103$90162004000600011 \& \operatorname{lng}=$ en\&nrm=iso $>$. Acesso em: 12 jul. 2012. doi: 10.1590/S0103-90162004000600011.

LEMAIRE, G.; CHAPMAN, D. Tissue fluxes in grazing plant communities. In: HODGSON, J.; ILLIUS, A.W. (Ed.). The ecology and management of grazing systems. Wallingford: CAB Internacional, 1996. p.3-36.

MAGALHÃES, A.F. et al. Influência do nitrogênio e do fósforo na produção do capim-braquiária. Revista Brasileira de Zootecnia, Brasília, v.36, n.5, p.1240-1246. 2007. Disponível em: <http:// www.scielo.br/scielo.php?script $=$ sci_arttext\&pid $=$ S 1516 $35982007000600004 \& \operatorname{lng}=e n \& n r m=i s o>$. Acesso em: 12 jul. 2012. doi: $10.1590 / \mathrm{S} 1516-35982007000600004$.

MARCELINO, K.R.A. et al. Características morfogênicas e estruturais e produção de forragem do capim-marandú submetido a intensidades e freqüências de desfolhação. Revista Brasileira de Zootecnia, Brasília, v.35, n.6, p.2243-2252. 2006. Disponível em: <http:// www.scielo.br/scielo.php?script $=$ sci_arttext $\&$ pid $=$ S 1516 35982006000800007\&lng=en\&nrm=iso>. Acesso em: 12 jul. 2012. doi: 10.1590/S1516-35982006000800007.

MARTUSCELLO, J.A. et al. Características morfogênicas e estruturais do capim-xaraés submetido à adubação nitrogenada e desfolhação. Revista Brasileira de Zootecnia, Brasília, v.34, n.5, p.1475-1482, 2005. Disponível em: <http:// www.scielo.br/scielo.php? script $=$ sci_arttext\&pid=S1516$35982005000500007 \& \operatorname{lng}=\mathrm{en} \& \mathrm{nrm}=\mathrm{iso}>$. Acesso em: $12 \mathrm{jul}$. 2012. doi: 10.1590/S1516-35982005000500007.

MATTOS, W.T. de; MONTEIRO, F.A. Respostas de braquiária brizantha a doses de potássio. Scientia Agrícola, Piracicaba, v.55, n.3, p.428-437, 1998. Disponível em: <http:// www.scielo.br/scielo.php? script $=$ sci_arttext $\&$ pid $=$ S0 103 $90161998000300011 \& \operatorname{lng}=\mathrm{en} \& \mathrm{nrm}=\mathrm{iso}>$. Acesso em: 12 jul. 2012. doi: 10.1590/S0103-90161998000300011.

OLIVEIRA, A.B. et al. Morfogênese do capim-tanzânia submetido a adubações e intensidades de corte. Revista Brasileira de Zootecnia, Brasília, v.36, n.4, p.1006-1013, 2007. Disponível em: <http:// www.scielo.br/scielo.php? script $=$ sci_arttext\&pid $=$ S1 1516 35982007000500004\&lng=en\&nrm=iso>. Acesso em: 12 jul. 2012. doi: doi.org/10.1590/S1516-35982007000500004.

PATÊS, N.M. da S. et al. Características morfogênicas e estruturais do capim-tanzânia submetido a doses de fósforo e nitrogênio. Revista Brasileira de Zootecnia, Brasília, v.36, n.6, p.1736-1741, 2007. Disponível em: <http://www.scielo.br/ scielo.php? script $=$ sci_arttext \& pid = S $1516-$ $35982007000800005 \& \operatorname{lng}=e n \& n r m=i s o>$. Acesso em: 12 jul. 2012. doi: 10.1590/S1516-35982007000800005.

PEREIRA, L.E.T. et al. Sward structure of marandu palisadegrass subjected to continuous stocking and nitrogen-induced rhythms of growth. Scientia Agrícola, Piracicaba, v.67, n.5, p.531-539, 2010. Disponível em: <http://www.scielo.br/scielo.php?script=sci_arttext\&pid=S010390162010000500006\&lng=en\&nrm=iso >. Acesso em: 12 jul. 2012. doi: 10.1590/S0103-90162010000500006. 
ROSOLEM, C.A. Interação do potássio com outros íons. In: YAMADA, T.; ROBERTS, T.L. (Eds.). In: SIMPÓSIO SOBRE POTÁSSIO NA AGRICULTURA BRASILEIRA, 2005, Piracicaba, SP. Anais... Piracicaba: FEALQ, 2005. p.239-260.

SBRISSIA, A.F. da et al. Tiller size/population density compensation in grazed coastcross bermudagrass swards. Scientia Agricola, Piracicaba, v.58, n.4, p.655-665, 2001. Disponível em: <http:// www.scielo.br/scielo.php? script=sci_arttext\&pid=S0103$90162001000400002 \& \operatorname{lng}=e n \& n r m=i s o>$. Acesso em: 12 jul. 2012. doi: 10.1590/S0103-90162001000400002.

SILVA, C.C.F. da. Morfogênese e produção de braquiárias submetidas a diferentes doses de nitrogênio. 2006. $72 \mathrm{f}$. Dissertação (Mestrado em Zootecnia) - Curso de Pós-graduação em Zootecnia, Universidade do Sudoeste da Bahia. 